\title{
Attributes to facilitate e-waste recycling behaviour
}

\author{
Nur Hidayah Senawi ${ }^{1}$ and Low Sheau-Ting ${ }^{2}$ \\ ${ }^{1}$ Department of Real Estate, Faculty of Geoinformation and Real Estate, Universiti Teknologi Malaysia, 81310 Skudai, Johor, Malaysia \\ ${ }^{2}$ Centre of Real Estate Studies, Institute for Smart Infrastructure and Innovative Construction, Universiti Teknologi Malaysia, 81310 \\ Skudai, Johor, Malaysia
}

\begin{abstract}
This study aims to identify the set of attributes to facilitate electronic waste (e-waste) behaviour among the community. E-waste disposal is increasing from year to year in parallel with increasing of global population. The short lifespan of electronics and poor e-waste recycling behaviour is among the main contributors to the steadily increasing of e-waste generated. Current recycling rate among the nation is lacking behind, which is only $10.5 \%$. A questionnaire survey has been conducted among the students in Universiti Teknologi Malaysia to evaluate the current e-waste recycling practice. The results showed that majority of the respondents did not recycle their ewaste on campus. Aggressive efforts is needed to realize the country's target of $20 \%$ recycling rate in year 2020 , one of the effective paths is to minimize e-waste generation via active e-waste recycling behaviour among the community. Extensive literatures have been reviewed to classify the attributes to facilitate effective e-waste recycling among the community. Total of five attributes that identified in this study which are Convenience of Ewaste Recycling Infrastruture and Services, E-waste Recycling Information, Incentives For E-waste Recycling, Reminder to Recycle E-waste And E-waste Recycling Infrastructure and Services. The set of attributes identified in this study may serve as guideline for the management in designing program to foster e-waste recycling behaviour among the community.
\end{abstract}

\section{Introduction}

Waste is among the most crucial problems facing by the world today. This is because the increasing of human population from day to day and the number of waste also increase [1]. The increasing trend of population growth will increase the solid waste produced. In urban area of Malaysia, the average waste produced is about 760,000 tone per day [2]. The increasing of WEEE will cause negative effect to the environment and to human itself [3]. Most of the electronic waste contain hazardous substances such as lead, cadmium, mercury, lithium and so on that can cause environmental pollution and negative effect to human health [3]. Even though the e-waste is harmful to the environment and to human health, the waste did not manage in a proper way such as recycling. The recycling rate of e-waste is still low and people do not practice it [4]. A questionnaire survey has been conducted in Universiti Teknologi Malaysia on the early of November 2015. The results shows that only $12 \%$ of the respondents who recycle their e-waste and $34 \%$ of the respondents keep their e-waste at the hostel and $24 \%$ of the respondents throw their e-waste as an ordinary waste in normal bin. The awareness level of the respondents is still low and makes them to not properly dispose their ewaste.

Author [5] in her research stated that only $22 \%$ of the respondents in Shah Alam City, Malaysia who recycle their e-waste and most of the respondents dispose their ewaste by store at home and sell as a second-hand equipment. In Malaysia, most of the universities did not manage their e-waste properly; for instance National University of Malaysia and Universiti Teknologi Malaysia (UTM). According to authors [6], management of e-waste in UKM is still at the early stage. The awareness level on e-waste is still low and this makes them to not properly dispose their e-waste [6]. Department of Environment (DOE) in Malaysia has published a set of guidelines on e-waste, known as the Guidelines for the Classification of Used Electrical and Electronic Equipment [5]. Even though this guidelines already established, but it do not give any information on how to manage the e-waste at the end of it lifespan [5]. Hence, residents do not know how to manage or recycle their e-waste properly since there are no guidelines for them to do so.

In order to realising the e-waste recycling behaviour among the community, identification of the right attributes need to be identified. By identifying the right attributes to facilitate the community to recycle their ewaste, it can encourage people to recycle their e-waste. The recycling rate will increase and achieve the target which is $20 \%$ of recycling rate in 2020 . If the recycling rate is increasing, it can also save the environment from the hazardous materials of the e-waste. Hence, there is a need to identify the attributes to facilitate e-waste recycling behaviour. Thus, the aim of this study is to identify the attributes that encourage the e-waste recycling behaviour. 


\section{Attributes of e-waste recycling behaviour}

Attributes of e-waste recycling behaviour can be described as the component that facilitate and encourage people to recycle their e-waste and thus to foster e-waste recycling behaviour. The attributes of e-waste recycling behaviour is important in order to encourage people to recycle their e-waste so that the e-waste can be disposed in an environmentally-friendly manner [7]. The attributes also can be used in implementing effective e-waste recycling management system [8]. By identifying the preferred attributes such as the convenience of accessibility to recycle bin, the management of the organisation can put the recycle bin that can easily be accessible by users. Hence, they can recycle their e-waste more conveniently. Based on the review of previous published literatures, this study has ascertained total of five attributes that fostering e-waste recycling behaviour among the community : (1) Convenience of E-waste Recycling Infrastructure; (2) E-waste Recycling Information; (3) Incentives for E-waste Recycling; (4) Ewaste Recycling Reminder; and (5) E-waste Recycling Infrastructure and Services. Further description on each attribute is presented in the followings.

\subsection{Convenience of E-waste Recycling Infrastructure}

The Convenience of E-waste Recycling Infrastructure means improved accessibility to recycling infrastructures. According to authors [9], several studies proved that the inconvenience of recycling infrastucture will lower the rate of people to participate in recycling activities. The more convenient the recycling infrastructure, the higher the rate of people participating in the recycling [10]. Other than inconvenience, any distance barriers or obstacles of recycle bins need to be removed in order to increase the rate of recycling [11]. Generally, this study identify three category distance of recycle bin which to facilitate e-waste recycling among the community; these including 100 meter distance to recycle bin, 100 meter to 500 meter distance to recycle bin and more than 500 meter to recycle bin.

The distance of less than 100 meter e-waste recycling infrastructure in this context means the e-waste recycling infrastructure such as recycle bin should be accessible within the distance of 100 meter. In a study conducted by authors [12] aimed to investigate sufficient number and positions of existing collection bins in Sidhapudur, Coimbatore, India using Geographical Information System (GIS). A model was developed based on the results of walking distance to drop the Municipal Solid Waste to the collection bin. There are three choices of distance which are 50 meter, 75 meter and 100 meter around the existing bins generated and the optimal distance was produced. The result shows that 75 meter of distance is the optimal distance to ensure good collection of municipal solid waste. The distance of 100 meter to
500 meter to e-waste recycling infrastructure such as recycle bin in this context means the e-waste infrastructure recycling should be allocated and accessed within the distance of 100 meter to 500 meter. Based on the previous study conducted by author [13] about the preferred attributes on waste segregation behaviour among the Malaysian campus community, the most preferred accessible distance to recycle bin by the students is 100 meter to 500 meter. The distance of more than 500 meter distance to e-waste recycling infrastructure such as recycle bin in this context means the recycle bins should be available and accessed within the distance of more than 500 meter. Distance plays an important attribute in order to foster the e-waste recycling behaviour among the community. The more convenience of the distance will encourage the community to recycle their e-waste.

\subsection{E-waste Recycling Information}

Information can be in various forms in order to raise knowledge and awareness about recycle, how to recycle and the benefits of e-waste recycling. According to authors [14], the producer of the product needs to provide the information on how to recycle and its effects when not disposed properly. These information is important in order for the obsolete e-waste to be treated effectively. In addition, authors [15] mentioned that recycling knowledge is important in determining the recycling behaviour among the students in University Sains Malaysia (USM).

Consumer awareness is important for the successfulness of e-waste recycling [16]. In order to raise the awareness, sufficient information about how to recycle, where to recycle and benefits of e-waste recycling should be provided [17]. The previous study has been done by authors [6] among the staffs and students in UKM. The results showed the awareness of ewaste management is still lacking seriously and in order to increase the awareness, they need to provide more information on e-waste management by teaching formally and informally and conducting seminars. In present context, information about e-waste recycling consists of two elements : (1) instructions to e-waste recycling, and (2) feedback on e-waste recycling.

Instructions to e-waste recycling is about providing the information to the community on how and where to recycle their e-waste. According to authors [8], the instructions can be done through educating the community on how and where to recycle in order to foster the recycling behaviour. According to authors [10], most of the consumers of mobile phone did not know that they can recycle their old and obsolete phone. This is due to the lack of information about waste collection and ewaste recycling. They also said that proper education and promotion from school, home, social media and other communication system can influence the mindset of people on the recycling of e-waste and ultimately building the awareness towards it. Hence, information about the instruction on e-waste recycling is important in 
order to enhance the e-waste recycling behaviour among the members of community.

Additionally, providing feedback on e-waste recycling is important to facilitate the practice of e-waste recycling among the community. In present context, feedback on e-waste recycling is about giving the feedback to the participants about the e-waste recycling information and rate of e-waste recycling after the ewaste recycling programme. Authors [16] proposed to establish a Global Recycle Network (GRN) in order to encourage e-waste recycling behaviour among consumers. In order to establish GRN, they need to provide the information feedback to product designers to improve recyclability. Authors [18] also stated that feedback about the performance of the recycling programme is important to encourage the recycling behaviour. In essence, feedback is essential to encourages people to recycle their e-waste. Information about ewaste recycling is among the important attributes in fostering e-waste recycling behaviour among the community. If there is no information about the e-waste recycling, the community might not be able to recycle their e-waste due to lacking of information such as did types of e-waste can be recycled.

\subsection{Incentives for E-waste Recycling}

Incentives for e-waste recycling is providing an incentive in form of monetary or non-monetary to the person or anyone who recycle their waste. According to authors [19], providing an incentive can foster the initial motivation for a sustainable activity. After the activity becomes part of their daily life, they will continue as their habits even without the extrinsic motivation. Thus, incentives can foster positive change in behaviour so that people will begin to recycle their e-waste. In present study, incentive is divided into two categories which are monetary incentive and non-monetary incentive.

A study by authors [20] on factors that influence people in Gaza City to recycle their domestic solid waste stated that more than half of the respondents choose financial rewards as the motivational factor to adopt recycling behaviour. A previous research conducted by authors [21] showed that Reuse, Recycling and Refurbishing (RRR) schemes collect more phones after offering the monetary incentives to the respondents. According to authors [22] monetary incentives can be in form of cash or voucher. The users will be given money if they recycle their e-waste or give back their e-waste to the producer. The result also stated that monetary incentives act as the most efficient incentives given to the respondents for successful of take-back services [22].

On the other hand, non-monetary incentives are incentives that do not involve cash payment. Authors [23] have conducted a study to exploring about how nonfinancial incentives contribute in motivating the workers to take care of their health and their retention in 16 countries. The result showed that non-monetary incentives are also important to motivate the workers to take care of their health because they feel valued by giving the non-monetary incentives to them. Hence, non- monetary also have the potential to motivate people to recycle their e-waste such as by giving appreciation letter for doing e-waste recycling, small gifts and invited them to join the e-waste recycling together afterwards. Monetary and non-monetary incentives play an important role in fostering e-waste recycling behaviour among the community. Both of the incentives will trigger the ewaste recycling behaviour among the community if they were applied among the community.

\subsection{E-waste Recycling Reminder}

According to authors [24] reminder defined as "auxiliary stimulation that is presented and remind the learner to display behaviour of interest at the appropriate time and appropriate circumstances". Reminder is useful in retaining sustainable behaviour [25]. Purpose of the reminder is to maintain the sustainable behaviour for long period [27]. Reminder also helps users to remember the sustainable practice which they tend to forget [27]. Authors [27] stated that verbal reminder and written reminder can increase about $22.1 \%$ of recycle rate participation. However, when only written reminders are given to residents, the recycle rate participation increases just by $2.4 \%$. In present study, there are two types of Ewaste Recycling Reminder which are written reminder and verbal reminder.

Authors [28] mentioned that sustainability behaviour tends to be forgotten. Similarly in the context of e-waste recycling, written reminder can be placed at corridors, common area with messages about benefits of e-waste recycling.

Authors [29] stated that verbal reminder is "words or instructions which direct a person to involve in the behaviour". For example, teachers in school remind and encourage the students to recycle their e-waste. A previous research conducted by authors [30] showed that verbal reminder can increase the consumption of fruit serving among school in the National School Lunch Program (NSLP). The percentage of the students who take and consume fruit serving increase significantly. Hence, the management may consider to add on verbal reminder in an effort to encourage the community to recycle their e-waste and to foster e-waste recycling behaviour. People tend to forgot easily and need to be reminding. Thus, reminder can be one of the important attributes to foster e-waste recycling behaviour among the community.

\subsection{E-waste Recycling Infrastructure and Services}

E-waste Recycling Infrastructure and Services is a facility or structures provided to dispose the e-waste. A previous research conducted in selected residential area in Kuala Lumpur, Malaysia found that recycling infrastructure is important attribute in fostering recycling behaviour [31]. Lacking of recycling facilities will decrease the consumers' intention to recycle and thus the recycling rate will be lower [32]. According to authors [18], in order to establish a proper management of solid waste on 
Maltese Island, physical infrastructure of waste management is among important elements. Furthermore, authors [33] stated that in order to improve the e-waste recycling among residents in Melaka, government should provide the recycling infrastructure so that residents know where to recycle their e-waste.

In present context, E-waste Recycling Infrastructure and Services consists of three elements which are e-waste drop-off site, e-waste recycling bin and e-waste collection service. E-waste drop off site is where the e-waste dustbin placed at public area where easily assessible such as bus stop and library [34]. The significance of recycling infrastructure and services in increasing recycling rate has been acknowledged in previous research. For instance study conducted by authors [34] has showed that the rate of recycling increased when the availability of drop-off recycling facilities are available at Prespa Park Vilage. Authors [32] in their research about recycling attitude and behaviour in university campus stated that campus management should provide more drop-off recycle bin such as at lift lobbies, café, hostel and library so that students can easily recycle their waste.

Previous research conducted by authors [35], a study about factors influencing the rate of recycling at Minnesota countries and the result showed that the increasing number of drop-off center has increased the recycling rates by $1.28 \%$. Study by authors [31] showed that the number of recycle bins need to be increased to improve the recycle rate among the household in Kuala Lumpur, Malaysia. ReCellular and Rechargeable Battery Recycling Corporation (RBBC) which is a non-profit organisation has established a collective service around the country in Brazil to collect the obsolete cell phones and the results showed that the e-waste recycling rate has successfully increased [36]. Infrastructure also important in encourage the community to foster e-waste recycling behaviour. If the e-waste recycling infrastructure is not provided, the community will not be able to recycle their e-waste and throw their e-waste in ordinary dustbin.

Table 1. Attributes to facilitate e-waste recycling behaviour.

\begin{tabular}{|c|c|}
\hline Attribute & Attribute Level \\
\hline $\begin{array}{l}\text { Convenience of E- } \\
\text { waste Recycling } \\
\text { Infrastructure }\end{array}$ & $\begin{array}{l}\text { Less than } 100 \text { meter } \\
\text { Distance to E-waste } \\
\text { Recycling Infrastructure } \\
100 \text { meter to } 500 \text { meter } \\
\text { Distance to E-waste } \\
\text { Recycling Infrastructure } \\
\text { More than } 500 \text { meter } \\
\text { Distance to E-waste } \\
\text { Recycling Infrastructure }\end{array}$ \\
\hline $\begin{array}{l}\text { E-waste Recycling } \\
\text { Information }\end{array}$ & $\begin{array}{ll} & \text { Instruction to E-waste } \\
\text { - } & \text { recycling. } \\
\text { Feedback on E-waste } \\
\text { recycling. }\end{array}$ \\
\hline $\begin{array}{l}\text { Incentives for E- } \\
\text { waste Recycling }\end{array}$ & $\begin{array}{ll}\text { - } & \text { Monetary Incentive. } \\
\text { - } & \text { Non-monetary Incentive. }\end{array}$ \\
\hline $\begin{array}{c}\text { E-waste Recycling } \\
\text { Reminder } \\
\text { Attribute } \\
\end{array}$ & $\begin{array}{l}\text { - } \quad \text { Written reminder. } \\
\text { - } \quad \text { Verbal reminder } \\
\text { Attribute level } \\
\end{array}$ \\
\hline
\end{tabular}

\begin{tabular}{|c|cl|}
\hline E-waste Recycling & $\bullet$ & E-waste Drop-off site. \\
Infrastructure and & $\bullet$ & E-waste Recycling bins. \\
Services & $\bullet$ & $\begin{array}{l}\text { E-waste collection } \\
\text { services. }\end{array}$ \\
\hline
\end{tabular}

\section{Conclusion}

Based on the review of literatures, present study has, proposed five attributes which are effective to facilitate ewaste recycling behaviour among the community. The five attributes are Convenience of E-waste Recycling Infrastructure, E-waste Recycling Information, E-waste Recycling Incentives, E-waste Recycling Reminder and E-waste Recycling Infrastructure and Services. In each of the attributes, it consists of two or three elements. The findings of the study may serve as a reference guide for the management in fostering electronic waste recycling behaviour among the community.

\section{Acknowledgements}

The authors gratefully acknowledge the research grant and financial support provided by the Ministry of Higher Education (MOHE) and Universiti Teknologi Malaysia (UTM), under the FGRS research grant number R.J130000.7809.4F506.

\section{References}

1. Tan, S. T., Ho, W. S., Hashim, H., Lee, C. T., Taib, M. R., \& Ho, C. S. Energy Conversion and Management. Energy, economic and environmental (3E) analysis of waste-to-energy (WTE) strategies for municipal solid waste (MSW) management in Malaysia., 102, 111-120 (2015)

2. Tarmudi, Z., Abdullah, M. L., \& Tap, A. O. M. Jurnal Teknologi. An overview of municipal solid wastes generation in Malaysia. 51(1), 1-15 (2009)

3. Perkins, D. N., et al. Annals of global health. E-waste: a global hazard. 80(4), 286-295 (2014)

4. Soo, V. K. and M. Doolan. Procedia CIRP. Recycling Mobile Phone Impact on Life Cycle Assessment. 15, 263-271 (2014)

5. Kalana, J. A.. International Journal of Environmental Sciences. Electrical and electronic waste management practice by households in Shah Alam, Selangor, Malaysia. 1(2), 132-144 (2010)

6. Chibunna, J. B., et al. Procedia-Social and Behavioral Sciences. The challenges of e-waste management among institutions: A case study of UKM. 59: 644649 (2012)

7. Chi, X., Wang, M. Y., \& Reuter, M. A. Journal of Cleaner Production. E-waste collection channels and household recycling behaviors in Taizhou of China. , 80, 87-95 (2014)

8. Wang, Z., et al. Journal of Cleaner Production. Willingness and behavior towards e-waste recycling for residents in Beijing city, China. 19(9-10), 977-984 (2011)

9. Saphores, J.-D. M., et al. Resources, Conservation and Recycling. Willingness to engage in a pro- 
environmental behavior: An analysis of e-waste recycling based on a national survey of U.S. households. 60: 49-63 (2012)

10. Sarath, P., et al. (2015). "Mobile phone waste management and recycling: Views and trends." Waste Managment.

11. Amuteya. N., Shackleton. C.M., Whittington-Jones, K.. Paper Recycling Patterns and Potential Interventions In The Education Sector: A Case Study of Paper Streams at Rhodes University, South Africa. Resour. Conserv. Recycl., 53, 237-242 (2009)

12. Nithya, R., Velumani, A., \& Kumar, S. R. R. WSEAS Transactions on Environment and Development. Optimal location and proximity distance of municipal solid waste collection bin using GIS: A case study of Coimbatore city. 8(4), 107-119 (2012)

13. Tee Sin Yee (2014). Attributes in Fostering Waste Segregation Behaviour. Master Thesis. Universiti Teknologi Malaysia

14. Nnorom, I. C., \& Osibanjo, O. Resources, conservation and recycling. Overview of electronic waste (e-waste) management practices and legislations, and their poor applications in the developing countries. 52(6), 843-858 (2008)

15. Ramayah, T., \& Rahbar, E. Management of Environmental Quality: An International Journal. Greening the environment through recycling: an empirical study. , 24(6), 782-801. (2013)

16. Takahashi, V. Osamu Kanzawa V. Makoto. FUJITSU Sci. Tech.. Establishment of global recycle network. 41.2 242-250 (2005)

17. Tanskanen, P. Acta materialia. Management and recycling of electronic waste. 61(3), 1001-1011 (2013)

18. Bezzina, F. H., \& Dimech, S. An International Journal. Investigating the determinants of recycling behaviour in Malta. Management of Environmental Quality, 22(4), 463-485 (2011)

19. Gneezy, U., Meier, S., Rey-Biel, P.,. When and why incentives (don't) work to modify behavior. J. Econ. Perspect. 25 (4), 191-210 (2011)

20. Omran, A., Sarsour, A. K., \& Pakir, A. H. K. The International Journal of Health Economics-IJHE. An Investigation Into The Factors Influencing The Participation Of Households In Recycling Of Solid Waste. 2(1), 4-19 (2012)

21. Ongondo, F. O., et al. Waste management. How are WEEE doing? A global review of the management of electrical and electronic wastes. 31(4): 714-730 (2011)

22. Li, B., Yang, J., Song, X., \& Lu, B.. Procedia Environmental Sciences. Survey on disposal behaviour and awareness of mobile phones in Chinese university students. 16, 469-476 (2012)

23. Churchard, C. Recycling \& Waste Management News and Information. Two Thirds of People Favor Financial Rewards for Recycling, says poll.. RWM, 22, August 2007. (2007).

24. Foxx, R.M.. Increasing Behavior of Severely Retarded and Autistic Individuals 81-96. Champaign, IL: Research Press. (1982)
25. Choong, W.W.. Paper presented at the 17th international symposium on society and resource management, Sabah. The process of fostering sustainable awareness and behavioiur among urban communities. (2011)

26. Low S.T. (2012). Factors Affecting Energy Conservation Behaviour of Students in Malaysia University. Ph.D. Thesis. Universiti Teknologi Malaysia

27. Spaccarelli, S., Zolik, E. \& Jason, L. A. Journal of Environmental Systems. Effects of Verbal Prompting and Block Characteristics on Participation in Curbside Newspaper Recycling. 19, $45-57$ (1990)

28. Armijo de Vega, C., Ojeda Benítez, S., and Ramírez Barreto, M. Waste Management. Solid Waste Characterization and Recycling Potential For a University Campus, 28, S21-S26. (2008)

29. Macduff, Gregory S., Patricia J. Krantz, and Lynn E. McClannahan. (2001). Prompts and Prompt-Fading Strategies For People With Autism. Making $A$ Difference: Behavioral Intervention For Autism. 3750.

30. Schwartz. M.B. International Journal of Behavioral Nutrition and Physical Activity. The Inflluence Of $A$ Verbal Prompt On School Lunch Fruit Consumption: A Pilot Study. 4, 6 (2007)

31.Zen, Irina Safitri, and Chamhuri Siwar. Habitat International. An analysis of household acceptance of curbside recycling scheme in Kuala Lumpur, Malaysia. 47, 248-255 (2015)

32. Chen, M.-F., Tung, P.-J. Environment and Behaviour. The moderating effect of perceived lack of facilities onconsumers' recycling intentions. 42, 824-844 (2010)

33. Tiep, H. S., Kin, T. D. Y., Ahmed, E. M., \& Teck, L. C. E-Waste Management Practices of Households in Melaka.

34. Grazhdani, D. Waste Management. Assessing the variables affecting on the rate of solid waste generation and recycling: An empirical analysis in Prespa Park. (2015)

35. Sidique, S. F., Joshi, S. V., \& Lupi, F. Resources, Conservation and Recycling. Factors influencing the rate of recycling: An analysis of Minnesota counties. 54(4), 242-249 (2010)

36. Johari, A., Alkali, H., Hashim, H., Ahmed, S. I., \& Mat, R.. Modern Applied Science. Municipal Solid Waste Management and Potential Revenue from Recycling in Malaysia. 8(4), p37. (2014) 